\title{
The Origins of Gold Brazing
}

Zur Geschichte der Löttechnik BY JOCHEM WOLTERS

Degussa, Frankfurt, 1976, 77 pages

Gold-based brazing alloys are finding an increasing number of applications in the assembly of aero-engines and of components in the nuclear engineering industry, mainly on account of their resistance to corrosion and to oxidation at high temperatures. The advent of new high-strength constructional materials for use in severe environments has naturally demanded joining materials suitable for the same types of conditions. Often the brazing methods adopted with gold alloys have to be of a sophisticated nature, employing either vacuum or an inert gas, although simpler techniques can be used for less critical applications, but by contrast with modern methods there is an extremely long history of gold brazing to produce the most remarkable and beautiful objects by what we should today consider the crudest of techniques. Some examples of these artefacts, including gold vessels excavated from Troy and from the royal graves at Ur, dating back to about 2500 B.C., were illustrated in Gold Bulletin in October 1973, but now we have a scholarly booklet sponsored by the

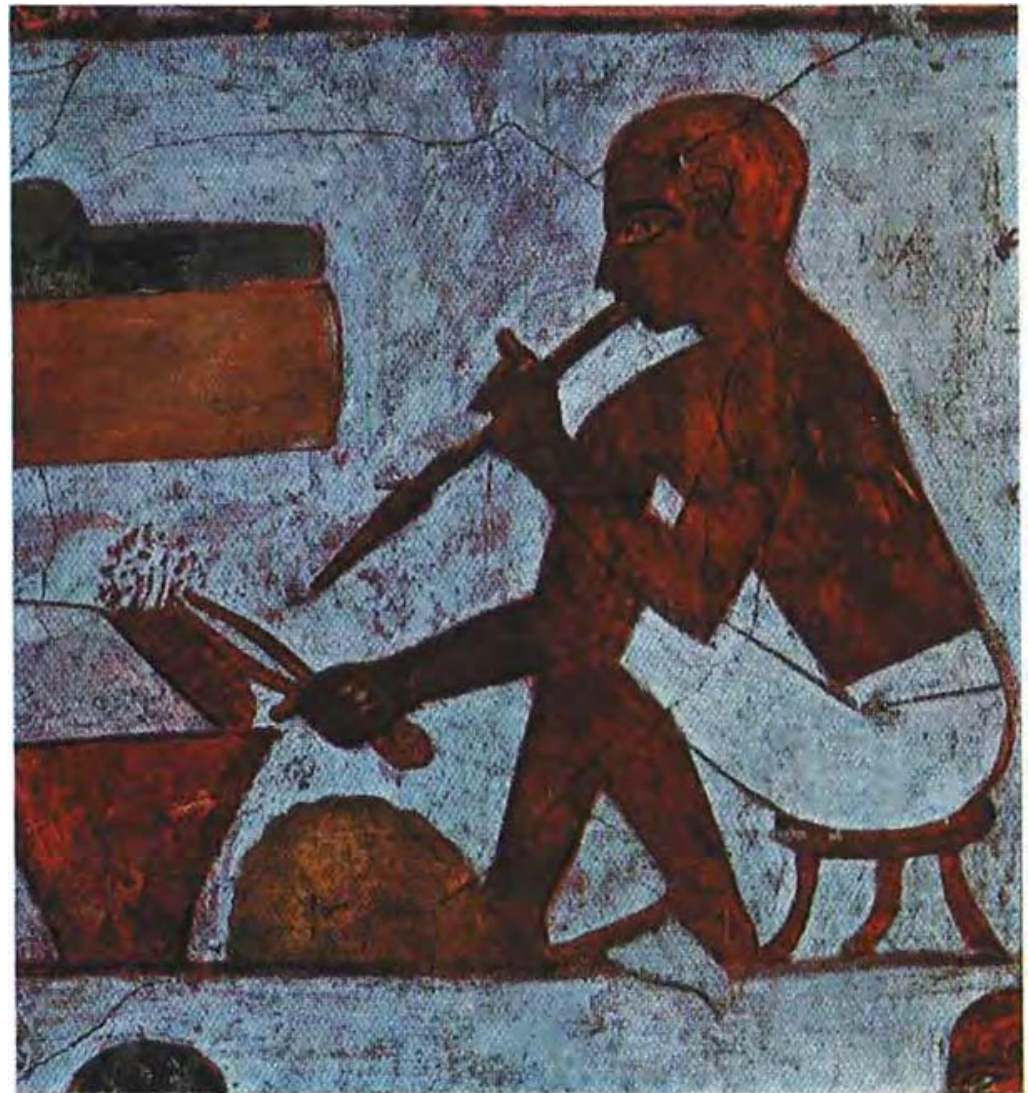

Some of the most beautiful objects made in ancient times were gold brazed with the most primitive of equipment. This wall painting, used as the title page in Jochem Wolters' book, is from the tomb of Rekh-mi-Re at Thebes in Egypt. Dating from about 1475 B.C., it shows a slave engaged in gold brazing with a charcoal fire in a clay bowl, a reed tipped with clay for a blowpipe, and tongs to hold the parts to be brazed well known German company,

Degussa, setting out the whole history of soldering, including of course soft soldering and silver brazing as well as gold brazing.

Following the discovery in about 4300 B.C. that copper ores could be reduced on a charcoal fire with the aid of a blowpipe, the concept of joining two metal parts by means of a solder can be dated to about 4000 B.C. somewhere in the Near East. By around 3400 B.C. both gold and silver brazing were being carried out by the Sumerians in the region that later became known as Mesopotamia. Soldering and brazing require of course not only a suitable alloy of lower melting point than those of the objects to be joined but also a means of achieving the necessary temperature and some kind of flux to prevent oxidation of the metal surfaces, and the author devotes some time to a discussion of both these latter requirements. Blowpipes made from reeds with a clay tip are known to have been used in Mesopotamia and later in Egypt, while some form of bellows can be traced in Egypt by about 2500 B.C. The earliest fluxes remain to some extent shrouded in mystery, but naturally-occurring soda may have been used, as well as alkalis obtained by the burning of plants, and the burnt lees of wine.

The author follows the development of brazing and soldering from its beginning in the Near East through to ancient Greece and Rome and onwards to the early and later Middle Ages in Europe, quoting (unfortunately without giving references) a great number of classical writers such as Homer, Hippocrates, Theophrastus, Aristotle, Strabo and Dioscorides 
down to Virgil, Pliny and Vitruvius for the Roman period.

In Europe a number of manuscripts such as the Mappa Clavicula and the Compositiones ad tingenda, written in the ninth century, give some details of soldering and brazing, but the most workmanlike account is that of the German monk who called himself Theophilus. His De Diversis Artibus, compiled in about 1125 , includes a full description of gold soldering and the preparation of a flux from beechwood ashes, soap, hog's lard and a mixture of copper salts.

In prehistoric times the choice of a suitable brazing alloy must have been by trial and error, but by about 500 B.C. it was realised that an alloy of one part of copper to two parts of gold was effective. From then on recipes for gold solders appear fairly frequently, ranging from around this composition to about one third copper.

By 1568 the great Italian goldsmith and sculptor Benvenuto Cellini was using gold-copper-silver alloys as brazing materials, and understood that, in the making of a succession of joints, "you must introduce a fresh alloy of silver and copper so as to prevent the solder of the time before from running".

Little further development seems to have occurred over the next 250 years, but by the very beginning of the nineteenth century the invention of the oxyhydrogen blowpipe by Robert Hare, Professor of Chemistry in the University of Pennsylvania-and the later discovery of acetylene by Friederich Wöhler-had made available reliable means of achieving high temperatures for gold brazing on a production scale, while the later development of physical metallurgy began to provide a number of gold alloys containing nickel and other elements suitable for various types of soldering and brazing.

Altogether this is a fascinating little book, in which one can trace an unbroken tradition of working methods from the ancient Near East through medieval Europe until quite recent times.

L. B. H.

\section{Gold Working Practice at Pompeii}

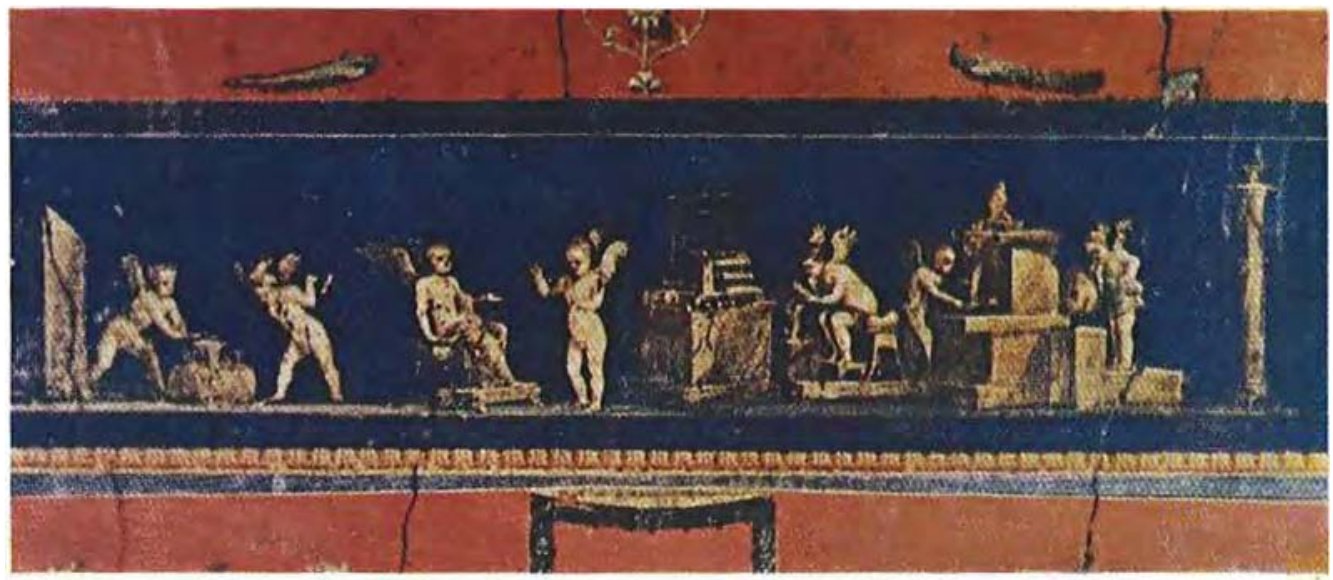

Among the most remarkable features of Pompeii, overwhelmed by an eruption of Vesuvius in A.D. 79 and now extensively excavated and preserved, is the series of charming and colourful wall paintings that decorate the House of the Vettii, an early building restored by two wealthy merchants, the brothers Aulus Vettius Restituto and Aulus Vettius Conviva, towards the end of the city's life. These show various scenes from the arts and occupations of the time, including the making and selling of oils and perfumes, the gathering of grapes and the making of wine, and the melting and working of gold. In all these scenes the artist made use of little Cupids to take the place of workmen. In the gold working scene the melting furnace at the right bears the head of Hephaestos, the patron of metal workers; on the left Cupids are forging an ingot with hammer and anvil. To the left of the melting furnace a blowpipe is being used, most probably for a soldering operation, and to the left again a customer is being served by another Cupid holding a balance to weigh the gold being purchased. 